\title{
The use of population viability analysis to identify possible factors contributing to the decline of a rare ungulate population in south-eastern Zimbabwe
}

\begin{tabular}{|c|c|}
\hline \multicolumn{2}{|c|}{$\begin{array}{l}\text { Authors: } \\
\text { Simon D. Capon }{ }^{1} \\
\text { Alison J. Leslie } \\
\text { Bruce Clegg }^{1}\end{array}$} \\
\hline \multicolumn{2}{|c|}{$\begin{array}{l}\text { Affiliations: } \\
{ }^{1} \text { Department of Conservation } \\
\text { Ecology and Entomology, } \\
\text { Stellenbosch University, } \\
\text { South Africa }\end{array}$} \\
\hline \multicolumn{2}{|c|}{$\begin{array}{l}{ }^{2} \text { Research Department, } \\
\text { Malilangwe Wildlife Reserve, } \\
\text { Zimbabwe }\end{array}$} \\
\hline \multicolumn{2}{|c|}{$\begin{array}{l}\text { Correspondence to: } \\
\text { Alison Leslie }\end{array}$} \\
\hline \multicolumn{2}{|c|}{$\begin{array}{l}\text { Email: } \\
\text { aleslie@sun.ac.za }\end{array}$} \\
\hline \multicolumn{2}{|c|}{$\begin{array}{l}\text { Postal address: } \\
\text { Private Bag X1, Matieland } \\
7602 \text {, South Africa }\end{array}$} \\
\hline \multicolumn{2}{|c|}{$\begin{array}{l}\text { Dates: } \\
\text { Received: } 20 \text { Apr. } 2012 \\
\text { Accepted: } 17 \text { Feb. } 2013 \\
\text { Published: } 05 \text { Apr. } 2013\end{array}$} \\
\hline \multicolumn{2}{|c|}{$\begin{array}{l}\text { How to cite this article: } \\
\text { Capon, S.D., Leslie, A.J. \& } \\
\text { Clegg, B., 2013, 'The use } \\
\text { of population viability } \\
\text { analysis to identify possible } \\
\text { factors contributing to the } \\
\text { decline of a rare ungulate } \\
\text { population in south-eastern } \\
\text { Zimbabwe', Koedoe 55(1), } \\
\text { Art. \#1081, } 9 \text { pages. http:// } \\
\text { dx.doi.org/10.4102/koedoe. } \\
\text { v55i1.1081 }\end{array}$} \\
\hline \multicolumn{2}{|c|}{$\begin{array}{l}\text { Copyright: } \\
\text { (C) 2013. The Authors. } \\
\text { Licensee: AOSIS } \\
\text { OpenJournals. This work } \\
\text { is licensed under the } \\
\text { Creative Commons } \\
\text { Attribution License. }\end{array}$} \\
\hline \multicolumn{2}{|l|}{ Read online: } \\
\hline 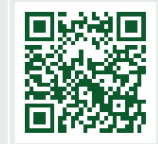 & $\begin{array}{l}\text { Scan this QR } \\
\text { code with your } \\
\text { smart phone or } \\
\text { mobile device } \\
\text { to read online. }\end{array}$ \\
\hline
\end{tabular}

Populations that are vulnerable to decline are of particular concern to wildlife managers and uncovering the mechanisms responsible for downward trends is a crucial step towards developing future viable populations. The aims of this study were to better understand the mechanisms behind the historic decline of the sable antelope, Hippotragus niger, population at the Malilangwe Wildlife Reserve (MWR), to assess its future viability and to use this analysis to determine key areas of breakdown in population growth and link these to potential limiting factors. VORTEX, a population viability model was used to assess the future viability of the sable antelope population and a sensitivity analysis was applied to identify the key areas of breakdown in growth. The sable population is currently viable, but remains highly vulnerable to changes in adult female survival, a factor which had the greatest influence on overall population fitness. Lion predation, impacting on the adult segment of the population, appeared to be the main factor responsible for the historic decline at the MWR.

Conservation implications: Sable generally occur at low densities in the lowveld region of Zimbabwe and, as such, populations are vulnerable to increases in mortality rates. The role of lions in driving the decline at the MWR suggests a need to control their numbers and develop prey refuges through improved management of artificial water.

\section{Introduction}

Crisis management is a common element of conservation biology (Begon, Harper \& Townsend 1996) because small or declining populations often require urgent action to prevent extinctions. Small or declining populations are particularly vulnerable to extirpation because they are governed by a high level of insecurity resulting from demographic and environmental stochasticity and spatial uncertainty (Begon et al. 1996). Grant and Van der Walt (2000) explain that at low densities populations are particularly at risk of extinction and any mortality in the population can be disastrous. Furthermore, it has been shown that at low densities stochastic events can wipe out small and declining populations altogether (Ginsberg, Mace \& Albon 1995).

Past studies have focused on identifying factors that influence population abundance, but less effort has focused on determining how age class survival rates may affect population dynamics (Gaillard, Festa-Bianchet \& Yoccoz 1998). Studies of population dynamics can often give insights into the possible causes of decline by identifying areas of breakdown in recruitment. They can also provide a better understanding of population trends and provide vital rates crucial to accurate viability analyses. Population viability analysis (PVA) is a useful tool for predicting future population sizes and assessing viability under a range of management scenarios (Brook et al. 2000). PVA makes use of real life-history data of a species or population to train the model and project the future population utilising stochastic variation in demography (Boyce 1992; Brook et al. 2000). Owing to their long generation time, large mammals were often excluded from population ecology studies because of the length of time taken to reveal interesting results (Gaillard et al. 1998). Gaillard et al. (1998) go on to suggest, however, that large mammals make ideal subjects for population studies because they can readily be distinguished into discrete age classes. This allows for accurate estimation of age-specific vital rates, an important component of any PVA. The low density of occurrence and strict seasonality of reproduction in sable antelope, Hippotragus niger, makes them ideal subjects for population studies and PVA may be a very useful tool in assessing the viability of isolated populations, such as that on the Malilangwe Wildlife Reserve (MWR). The long-term growth rate of a population can be used as a direct measure of fitness and, as such, a sensitivity analysis assessing the sensitivity of the long-term growth rate to changes in vital rates can provide important clues as to the areas most susceptible to breakdown in the growth of a population. 
The sable population at the MWR in the south-eastern lowveld of Zimbabwe declined from over 200 animals in 1994 to only 62 by 2005 . This was followed by a period of relative recovery where the population increased to 77 by 2010, but the population still remains highly vulnerable. This declining trend (1994-2005) is not unique to the MWR and is similar to that reported for sable in the Kruger National Park (KNP), South Africa. Grant and Van der Walt (2000) note that the sable population in the KNP declined from 2240 in 1986 to only 505 by 1999 . A number of hypotheses have been put forward to explain the decline, including: competition with other herbivores (Harrington et al. 1999), increased predation (Grant \& Van der Walt 2000; Owen-Smith, Mason \& Ogutu 2005), rainfall variation (Owen-Smith et al. 2005), disease (Nijhof et al. 2005; Oosthuizen et al. 2008) and habitat loss (Grant \& Van der Walt 2000). An understanding of the population dynamics of sable on the MWR may give insights into the factors responsible for the decline and could, in turn, help to formulate a mitigating management strategy.

The main objectives of this study were, (1) to gain an understanding of the dynamics of the sable population at the MWR and assess its future viability, (2) to identify the possible factors leading to the decline of the species and (3) to discuss the implications thereof. We used a PVA to broadly assess the viability of the sable population under different scenarios and further applied the PVA to a sensitivity analysis of the overall fitness of the sable population.

\section{Methods \\ Study site}

The MWR (39 378 ha) is located in the south-eastern lowveld of Zimbabwe. The reserve is bordered by the Gonarezhou National Park to the south, the Hippo Valley Game Section to the west and by communal land to the north and east (Figure 1). The area has three distinct seasons: a hot, wet season from November to March, a cool, dry season from May to August and a hot, dry season from September to October. The long-term average annual rainfall for the area is $562.22 \mathrm{~mm} \pm 193.81 \mathrm{~mm}$, measured at Malilangwe Headquarters from 1951 to 2009 (Figure 2). Between March 2009 and January 2011, the study period, the MWR received $785.40 \mathrm{~mm}$ of rainfall and the average monthly maximum and minimum temperatures were $30.50{ }^{\circ} \mathrm{C} \pm 3.20{ }^{\circ} \mathrm{C}$ and $17.60{ }^{\circ} \mathrm{C} \pm 3.88^{\circ} \mathrm{C}$, respectively. The vegetation is dominated by a variety of open Colophospermum mopane woodland, with the Malilangwe sandstone range being characterised mostly by Brachystegia woodlands. The property has been classified into 38 vegetation types based on the species composition of both the woody and herbaceous layers, the structure of the woody component and the ecological factors that influence the plant communities (Clegg 2010).

\section{Population data collection}

Data on the population structure of sable antelope at the MWR were collected between March 2009 and January 2011. To facilitate this, an adult female from four of the sable herds at the MWR was immobilised by a licensed professional using a combination of $6.0 \mathrm{mg}$ M99 and $1.0 \mathrm{mg}$ medetomidine and fitted with a GPS-VHF collar (Qauntum 5000, weight: 700 g; Telemetry Solutions, Concord, California). Once the collar had been securely fitted, the anaesthesia was reversed using $18.0 \mathrm{mg}$ M5050 and $2.5 \mathrm{mg}$ Antisedan and, in all cases, the collared animals moved off unharmed, rejoining their respective herds within 1-4 h. A fifth herd, the only other herd on the MWR, was monitored opportunistically over the study period, allowing us to ensure all sable individuals, except for itinerant males, were accounted for. Although not fitted with a collar, this herd was encountered on average every 2-3 weeks and from these encounters a clear demographic structure of the herd was gathered.

The VHF signal emitted by the collars was used to locate each herd every 3 days. On locating a herd, a total count was made, followed, where possible, by an age-sex specific count. Individuals were assigned to either male adult (3+ years),

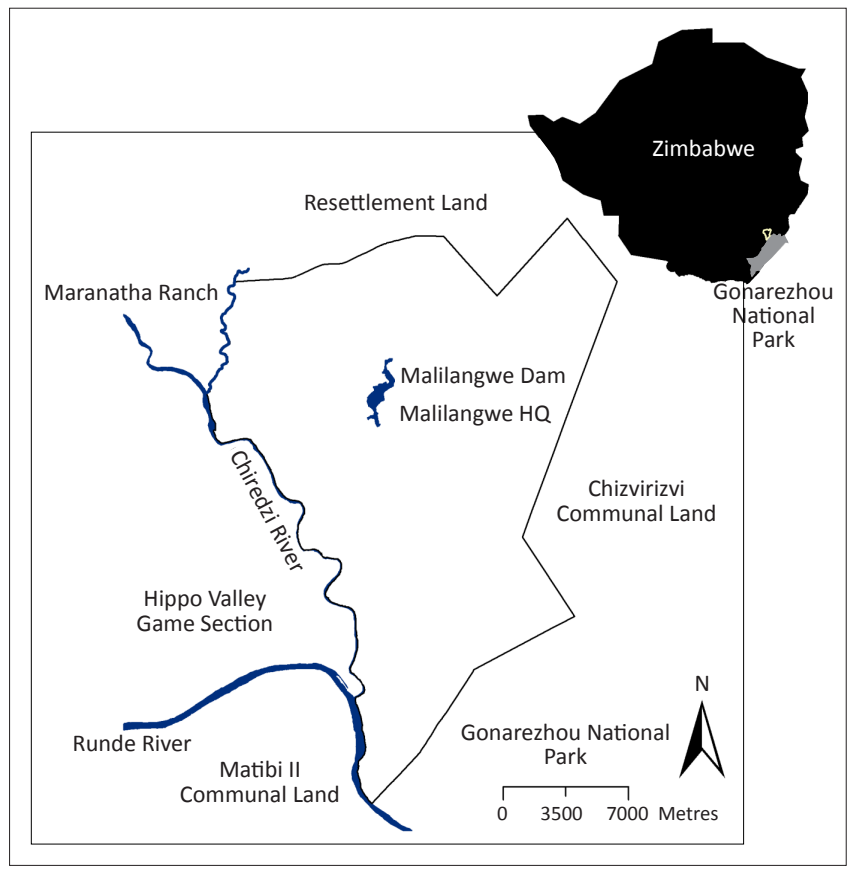

FIGURE 1: Map showing the location of Malilangwe Wildlife Reserve.

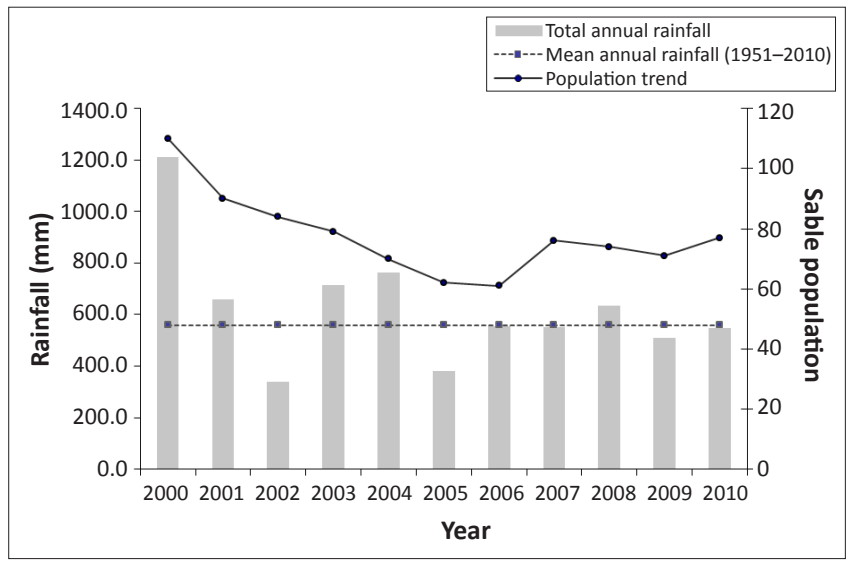

FIGURE 2: The historical trend in the sable population on the Malilangwe Wildlife Reserve between 2000 and 2010. Evident are two distinct trends in the population from 2000 to 2005 and from 2005 to 2010. 
female adult ( $3+$ years), sub-adult male ( $2-3$ years), sub-adult female ( $2-3$ years), yearling (1-2 years) and juvenile ( $0-1$ year) age classes, according to Grobler (1980a), who suggested the use of a combination of horn characteristics and physical appearance for classification. By combining data from the counts of each herd, changes in the number of animals in each age class were recorded over the study period. In most cases, all four collared herds were seen in 1 day and the fifth herd was encountered at least once every fortnight. For all the female age-classes and the male juvenile, yearling and adult age-classes, if an individual disappeared and did not return before the next breeding cycle, that individual was considered to be dead. Consistent monitoring of sub-adult males was more difficult as they do not remain with the herds until adulthood; accurate observations were therefore not possible. It was not considered necessary to recognise each individual sable because the entire population was being monitored over the study period. During the wet season, sable herds often split up into smaller units, but in nearly all cases reliable counts were achieved at least twice per month. This provided a near-continuous data set for the entire study period, covering two calving seasons. These demographic data were then used to estimate vital rates and develop a baseline for the PVA.

\section{Age class mortality rates}

Age-specific mortality rates for sable were calculated for each breeding cycle of the study period using population data gathered during the fieldwork phase of the study. The start and end of the breeding cycle was taken as April and January, respectively, because February-March is the calving season for sable at the MWR. This meant that by April a new crop of calves would emerge pushing existing animals into the next age-class. Data derived from the life tables were used to calculate age-class mortality rates using the formula developed from methods described in Caughley (1966):

$Q c=\left[\left\{N \chi-N \chi_{+1}\right\} / N \chi \times 100\right]$

[Eqn 1]

Where $Q c$ is the mortality rate of age class $c, N \chi$ is the number of individuals in age class $c$ at time $\chi$ and $N \chi_{+1}$ is the number of individuals still alive in age class $c$ at time $\chi_{+1}$. This method of deriving mortality rates was employed for all but the juvenile age-class. The mortality rate for the juvenile age-class was calculated by dividing the number of calves alive at the end of the breeding cycle by 0.96 times the number of adult females in the herd at the beginning of the cycle and subtracting this value from one. This figure was then multiplied by 100 to convert the mortality rate into a percentage. The value of 0.96 was derived from observations made from sable antelope at the MWR during the 2009 and 2010 breeding seasons, where $96 \%$ of adult females fell pregnant and were assumed to give birth to a healthy calf. Pregnancy was estimated somewhat subjectively following Grobler (1980b), who used the shape of the stomach and presence of a bulging udder to determine pregnancy. In all but the adult age-class, no distinction in mortality rate was made between male and female sable. At the younger stages, it was not considered necessary as both males and females stay within the herd and in theory face the same risk of mortality. Determining a mortality rate for sub-adult males was more difficult because they often leave the herd making it impossible to monitor them regularly. The same mortality estimates developed for sub-adult female sable were therefore used for sub-adult males, possibly a rather conservative estimate for the part of sub-adult males.

\section{The population viability analysis model}

For the analysis and simulation of the PVA, VORTEX version 9.99b was used (Lacy, Borbat \& Pollack 2009). The model was developed to stochastically simulate the risk of extinction faced by a species. The VORTEX model takes into account a description of the species reproduction system and reproductive rates, a specified age structure, agespecific mortality rates, catastrophic events, demographic and environmental stochasticity, density dependence and options for the harvest and augmentation of the population.

Assessing the viability of the sable population at the MWR using VORTEX involved a stepwise process. The first stage entailed calibrating the model and replicating the historical trend of the population. An analysis of the historical population trend revealed two distinct periods. The first was the period of population decline from 2000 to 2005 and the second, the period of population recovery from 2005 to 2010. Accordingly, the calibration of the population model was divided into these two distinct periods. The second stage of the process involved projecting the population forward 100 years using data ratified during the calibration of the model for the periods 2000-2005 and 2005-2010. Baseline settings used in the model are described in the following subsections.

\section{Scenario settings}

Although five separate sable herds exist on the MWR, the reserve is essentially a closed system and therefore the MWR sable were described as a single population. During the calibration process, the PVA was simulated 500 times over two 5-year periods, from 2000 to 2005 and from 2005 to 2010. Following calibration, the model was again simulated 500 times for a period of 100 years in each of the subsequent scenarios.

\section{Reproduction system, age of first reproduction and longevity}

Age of first reproduction in the VORTEX model was set at 3 and 6 years old for female and male sable, respectively. Based on personal observations at the MWR and discussions with other experts, under natural conditions of predation, disease and environmental variability, the maximum age of reproduction in sable was set at 12 years of age.

\section{Reproduction rate}

In the study, it was assumed from field observations, that $96 \%$ of the adult females in the population would fall pregnant each year and each would produce a single calf. From observations made over two calving seasons at the 
MWR, the calf sex ratio at birth was estimated at 1:1. A breeding population of $29 \%$ of males was used and this was determined by dividing the number of dominant, territorial bulls seen to be mating with females by the number of adult bulls in the population.

\section{Catastrophic events}

Catastrophic events by their very nature are unpredictable, usually with devastating consequences, making managing for a catastrophe almost impossible. The purpose of this study was not to create a generic population model for sable but to investigate specifically what drove the decline in sable at the MWR using a population viability tool. As no catastrophic events were encountered over the period under review, they were excluded from the model.

\section{Initial population}

Data on the size of the sable population (Figure 2) in 2000 and 2005 on the MWR used in calibrating the model were taken from the annual aerial census data conducted by helicopter between 2000 and 2010 (Goodman 2009). As the age-specific population structure was unknown in both 2000 and 2005, the model was run using a stable age distribution in both scenarios to test the baseline data and calibrate the model. Once calibrated, the model was simulated using the age specific population structure (Table 1) determined at the beginning of the study period in March 2009.

\section{Carrying capacity}

A value of 200 was used in the PVA as a measure of carrying capacity (K) on the MWR and was taken from historical population estimates made by Booth (1980). It was not considered essential to use an entirely precise figure for $\mathrm{K}$, as the purpose of this study was to assess the risk of extinction of the current population and to assess the trend of the population under a number of different scenarios, rather than being concerned with actual figures for final population size after 100 years.

\section{Supplementation and harvest}

The release of a further 30 sable took place in 2011, the first supplementation of the population since 1994. The population model was run using current population estimates, as well as testing the effect of boosting the population with a further 30 individuals (10 adult females, 5 sub-adult males, 5 sub-adult females, 5 juvenile males and 5 juvenile females). No harvest of the sable population was included in the PVA.

In the VORTEX model, standard deviation in vital rates or carrying capacity as a result of environmental variance was stated as zero in all cases. Although it was recognised that environmental variation may well cause year to year variation in survival, no data were available on the actual effect of this variation. It was therefore decided not to include this effect, but rather to work with a relatively simplified version of the model. Table 2 shows a summary of those baseline data input for each scenario of the VORTEX model.

\section{Model scenarios}

In Scenario 1, the current conditions using vital rates recorded over the study period were simulated and these were tested against the trend observed from 2005 to 2010. Historical data from scout patrol reports on sable carcasses were then used to estimate a factoring for the adjustment of current mortality estimates for the second scenario. Five times as many sable carcasses were found by scouts on patrol during

TABLE 1: Demographic structure of the sable population on the Malilangwe Wildlife Reserve in March 2009.

\begin{tabular}{lcc}
\hline Age (years) & Female sable & Male sable \\
\hline $0-1$ & 6 & 6 \\
$1-2$ & 7 & 5 \\
$2-3$ & 4 & 4 \\
$3-4$ & 5 & 4 \\
$4-5$ & 5 & 3 \\
$5-6$ & 4 & 2 \\
$6-7$ & 4 & 1 \\
$7-8$ & 4 & 1 \\
$8-9$ & 4 & 0 \\
$9-10$ & 3 & 0 \\
$10-11$ & 3 & 1 \\
$11-12$ & 1 & 0 \\
\hline Total & $\mathbf{5 0}$ & $\mathbf{2 7}$ \\
\hline
\end{tabular}

TABLE 2: Summary of baseline data used in the VORTEX model under various scenarios.

\begin{tabular}{|c|c|c|c|c|}
\hline Parameter & $\begin{array}{l}\text { Scenario 1: } \\
\text { Calibration } \\
\text { 2005-2010 }\end{array}$ & $\begin{array}{l}\text { Scenario 2: } \\
\text { Calibration } \\
\text { 2000-2005 }\end{array}$ & Scenario 3 & Scenario 4 \\
\hline Number of iterations & 500 & 500 & 500 & 500 \\
\hline Number of years & 5 & 5 & 100 & 100 \\
\hline $\begin{array}{l}\text { Age of first offspring - } \\
\text { Female (years) }\end{array}$ & 3 & 3 & 3 & 3 \\
\hline $\begin{array}{l}\text { Age of first offspring - } \\
\text { Male (years) }\end{array}$ & 6 & 6 & 6 & 6 \\
\hline $\begin{array}{l}\text { Maximum age of } \\
\text { reproduction (years) }\end{array}$ & 12 & 12 & 12 & 12 \\
\hline $\begin{array}{l}\text { Maximum broods per } \\
\text { year }\end{array}$ & 1 & 1 & 1 & 1 \\
\hline Offspring per brood & 1 & 1 & 1 & 1 \\
\hline $\begin{array}{l}\% \text { Adult females } \\
\text { breeding }\end{array}$ & 96 & 96 & 96 & 96 \\
\hline $\begin{array}{l}\% \text { Adult males } \\
\text { breeding }\end{array}$ & 29 & 29 & 29 & 29 \\
\hline $\begin{array}{l}\text { Female mortality from } \\
\text { age } 0-1 \text { years }(\%)\end{array}$ & 57 & 57 & 57 & 57 \\
\hline $\begin{array}{l}\text { Female mortality from } \\
\text { age } 1-2 \text { years }(\%)\end{array}$ & 6 & 6 & 6 & 6 \\
\hline $\begin{array}{l}\text { Female mortality from } \\
\text { age } 2-3 \text { years }(\%)\end{array}$ & 8 & 40 & 8 & 40 \\
\hline $\begin{array}{l}\text { Mortality of female } \\
\text { sable older than } 3 \\
\text { years (\%) }\end{array}$ & 4 & 20 & 4 & 20 \\
\hline $\begin{array}{l}\text { Male mortality from } \\
\text { age } 0-1 \text { years }(\%)\end{array}$ & 57 & 57 & 57 & 57 \\
\hline $\begin{array}{l}\text { Male mortality from } \\
\text { age } 1-2 \text { years }(\%)\end{array}$ & 6 & 6 & 6 & 6 \\
\hline $\begin{array}{l}\text { Male mortality from } \\
\text { age } 2-3 \text { years }(\%)\end{array}$ & 8 & 40 & 8 & 40 \\
\hline $\begin{array}{l}\text { Mortality of male sable } \\
\text { older than } 3 \text { years }(\%)\end{array}$ & 9 & 45 & 9 & 45 \\
\hline Initial population size & 62 & 110 & 77 & 77 \\
\hline Carrying capacity (K) & 200 & 200 & 200 & 200 \\
\hline Supplementation & 0 & 0 & $0^{\mathrm{a}} ; 30^{\mathrm{b}}$ & $0^{\mathrm{a}} ; 30^{\mathrm{b}}$ \\
\hline
\end{tabular}

a, No augmentation of the population.

b', Augmentation of the population by 30 individuals ( 10 adult females, 5 sub-adult females, 5 sub-adult males, 5 juvenile females and 5 juvenile males). 
the period 2000 to 2005 than during 2005 to 2010, despite a relatively even patrol effort between the periods (two-sample $t(5)=-1.39, p=0.22)$. Of the carcasses discovered, $88 \%$ were from the adult and sub-adult age classes, hence mortality rates for only the adult and sub-adult age classes were increased by a factor of five. It was impossible to estimate a factoring for the juvenile age class as juvenile carcasses are notoriously difficult to find, often being completely eaten leaving no trace (Owen-Smith \& Mills 2008). The new vital rates developed from the factoring process were then tested in the model against the observed trend from 2000 to 2005. In Scenarios $3 a$ and $4 a$, the population was projected forward by 100 years using the vital rates derived for Scenarios 1 and 2, respectively. Additionally, the effect of augmenting the sable population with 30 individuals was simulated in Scenarios $3 b$ and $4 b$.

\section{Sensitivity analysis}

In the sensitivity analysis, the VORTEX model was run varying survival of each age class in turn, whilst keeping all others at their average value over the study period (2009-2011). The percentage change in survival rate for each age class was plotted against the VORTEX output value of mean long-term population growth rate $(r)$. This allowed the determination of the sensitivity of the long-term population growth rate, and hence overall fitness, to changes in the survival rates of each age class.

\section{Results}

\section{Demographic parameter estimation, population size and reproductive rate}

Demographic parameters were calculated from the field data collected over the entire study period (Table 2). In general, mortality rates (MR) were considered low for all but the juvenile age class $(\mathrm{MR}=57 \%)$. Adult female sable had the lowest mortality rate of all the age classes $(\mathrm{MR}=4 \%)$, followed by the yearling age class $(\mathrm{MR}=6 \%)$. Adult male mortality rate was more than double that of adult females at $9 \%$ and this was reflected in the sable population structure at the MWR. From 2000 to 2005, the sable population declined from 110 individuals to only 62 (Figure 2). The population then began to stabilise and had grown to 77 individuals by 2010. During the 2009-2010 breeding season, 21 out of 22 adult females were pregnant and due to give birth in March 2010, but by April 2010 there were only nine surviving calves. This suggests that calves were either still-born or died during the hiding phase after birth. Notably though, three calves, all from the same herd, were recorded alive soon after birth and seemed healthy, but by May 2010 this herd had no calves accompanying them, indicating that many more calves may have been born healthy but perished during the calf hiding phase.

\section{Replicating the historical population trend}

Results from the overall training and testing of the model proved highly comparable with that of the observed population trend (Figure 3). During the 5-year period, 2000-2005, the modelled population declined from a total of 110 individuals to only 61 by 2005 . This was similar to observed trends which showed a decline from the same initial population to only 62 individuals over the same period. VORTEX predicted a growth rate of -0.1209 (s.d. $=0.0777$ ) and a probability of extinction within the 5 years of zero.

The modelled population projected from 2005 to 2010 tracked the observed trend closely (Figure 4), increasing from an initial population of 62 individuals to 79 by 2010 . Similarly, the observed population increased from 62 to 77 over the same period, falling well within the $95 \%$ confidence limits set by the modelled population. The modelled and observed populations increased at average rates of $4.80 \% \pm 5.02 \%$ and $4.90 \% \pm 12.6 \%$ per year, respectively.

\section{Future population viability}

Using the vital rates estimated for the period 2000-2005, the modelled population is predicted to decline sharply at an overall rate of $16.7 \%$ per annum (Figure 5), with extinction predicted after just 18 years. Augmenting the population

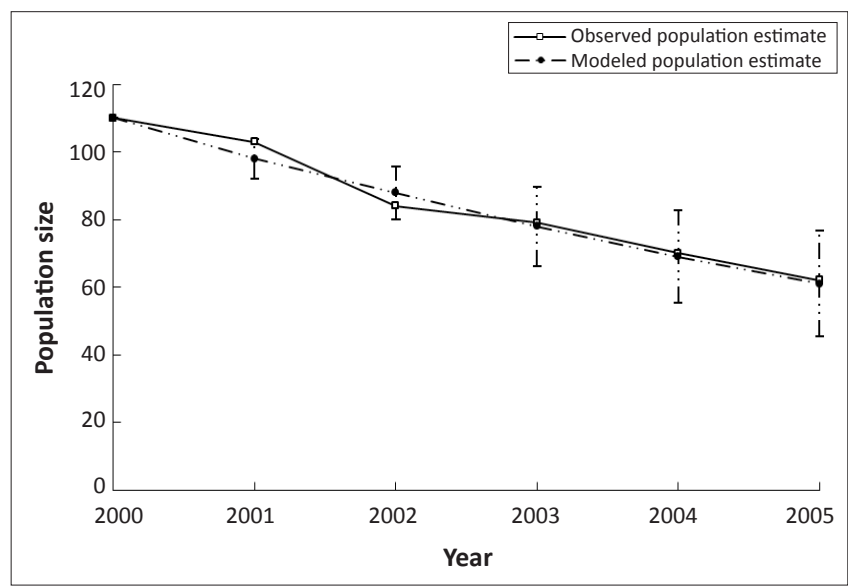

Error bars represent $95 \%$ confidence limits set out by the modelled population.

FIGURE 3: Modelled versus observed trends in the sable population on the Malilangwe Wildlife Reserve from 2000 to 2005.

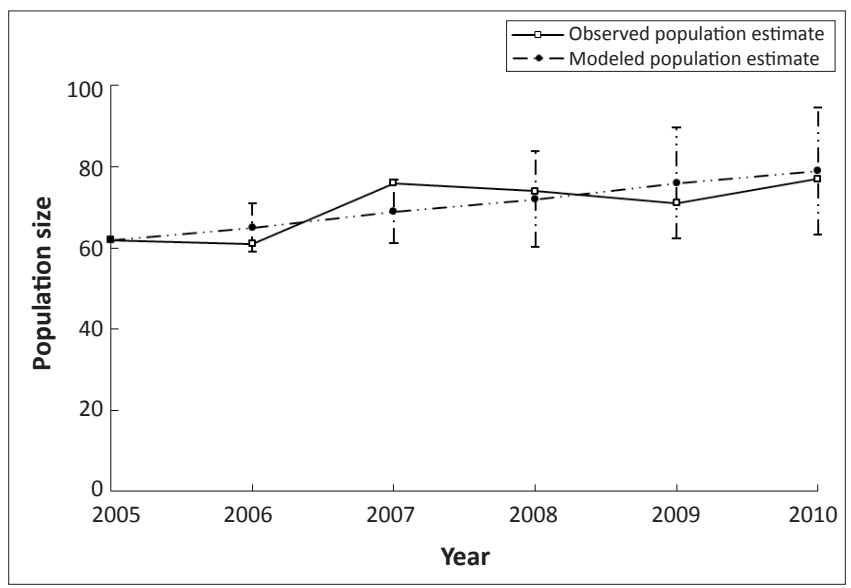

Error bars represent $95 \%$ confidence limits set out by the modelled population.

FIGURE 4: Modelled versus observed trends in the sable population on the Malilangwe Wildlife Reserve from 2005 to 2010. 
with the further 30 sable will not curb this trend and the sable population is predicted to remain extant on the MWR for only the next 22 years. The addition of the 30 sable to the population slows the decline to $16.1 \%$ per annum, but there remains no chance of recovery for the population under these circumstances.

Using the vital rates estimated for the period 2005-2010, the sable population is predicted to increase steadily at a rate of $4.9 \%$ per year, quickly stabilising at K (Figure 5). In this case, the population reaches $\mathrm{K}$ after only 30 years and the model predicts no chance of extinction within 100 years. Under these conditions, supplementation of the population with a further 30 sable causes the population to increase again at a rate of $4.9 \%$ per annum, stabilising around $\mathrm{K}$ after just 20 years. The model forecasts no chance of extinction within the 100 year period.

\section{Population sensitivity}

The sensitivity of the population growth rate to changes in survival of the different age classes is shown in Figure 6. Proportional changes to adult female survival had the greatest effect on the average long-term population growth rate. As little as a $10 \%$ reduction in survival of adult females led to a negative growth rate $(r=-0.007)$ in the population. By comparison, a reduction of $25 \%$ in the survival rate of the other age classes still resulted in positive growth in the overall population. Though marginally so, sub-adult survival had the next greatest effect on the overall population growth rate, with a $25 \%$ reduction in survival reducing population growth to 0.006 per year. Adult male survival had the least impact, if any, on the overall growth rate of the population.

\section{Ethical considerations}

All work was carried out under the guidance of the Malilangwe Trust and its code of conduct. In all cases, licensed professionals and veterinarians were used to perform immobilisations and any risks to the animals were kept to an absolute minimum (see 'Acknowledgements').

\section{Trustworthiness}

All data were collected using standard scientific procedures and, as such, the results are considered to be entirely objective and accurate. Unfortunately, the nature of ecological work means that some level of inconsistency is achieved, in that the results may not be directly repeatable if the study were performed over another time period because of the nature of variation in natural systems. However, this does not detract from the findings of the research in any way whatsoever.

\section{Discussion}

There have been heated debates in the literature regarding the value and accuracy of PVA models for predicting future population trends (Coulson et al. 2001; Ellner et al. 2002; Taylor 1995). In spite of this, PVA has been employed widely as a tool for assessing the vulnerability of threatened populations and for evaluating possible options for their recovery (Brook et al. 2000; Cancino, Rodriguez-Estrella \& Miller 2010; Gusset et al. 2009; Kelly \& Durant 2000). The usefulness of a PVA model, however, depends entirely on the quality and accuracy of the baseline data (Coulson et al. 2001). The probability of extinction of a population is influenced by both uncertainties in the natural environment, as well as uncertainty in the estimation of parameters used in the model (Taylor 1995). Although environmental variation plays a role in varying the predictions of the model, uncertainty in the estimation of input parameters had a much greater effect on the overall output (Taylor 1995). McLoughlin and Owen-Smith (2003) state that models that ignore predation pressure and take into account only demographic and environmental stochasticity may greatly underestimate extinction risk. In this study, the data used were collected intensively over a 2-year period to derive vital rates for the population. These rates were tested

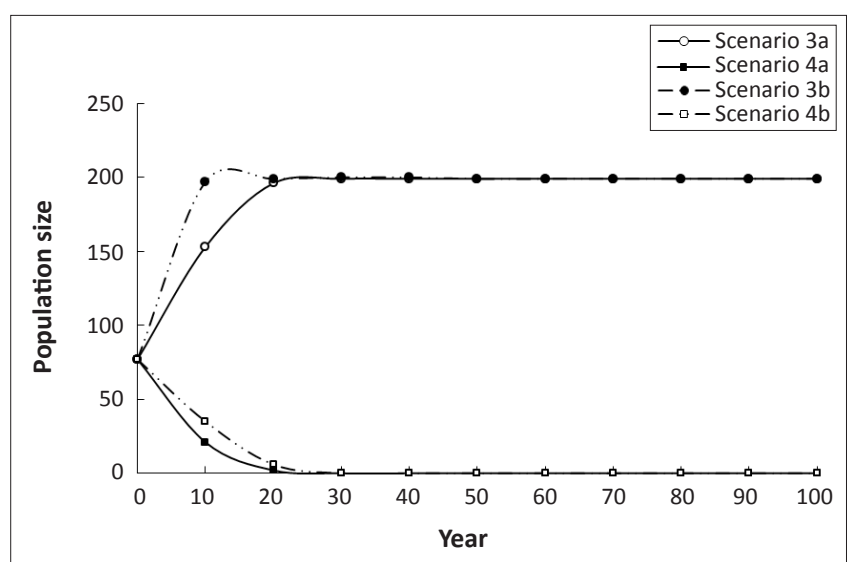

FIGURE 5: Mean sable population trend on the Malilangwe Wildlife Reserve over 100 years, modelled using estimates of vital rates taken from 2000 to 2005 and 2005 to 2010 ( $3 a$ and $4 a$ ). Also shown are the effects of augmenting the population with 30 sable ( $3 b$ and $4 b$ ).

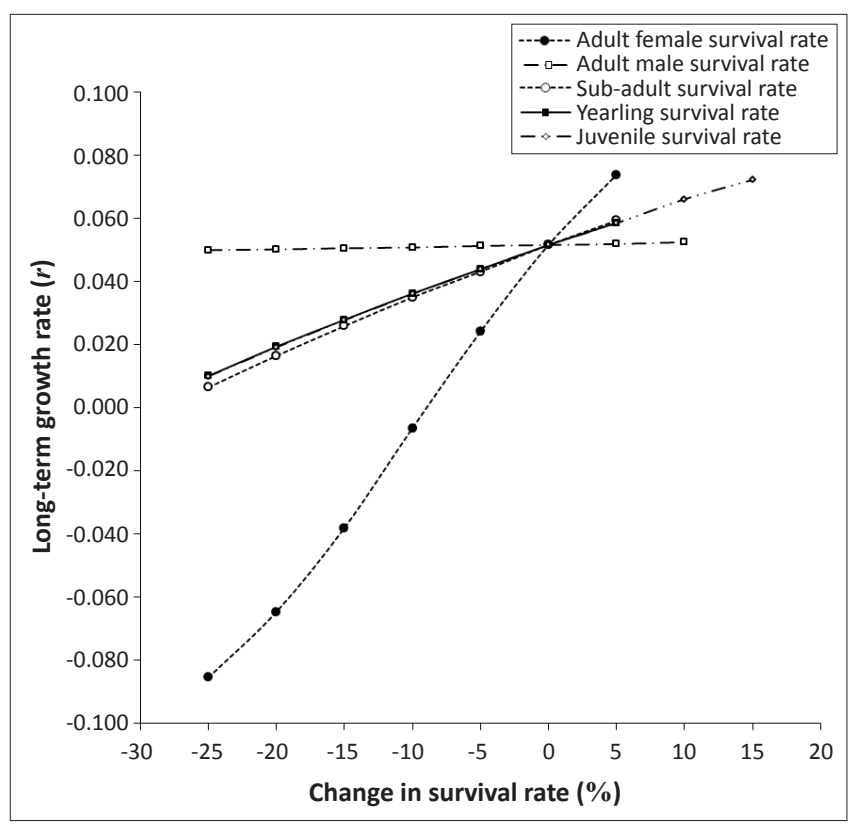

The truncation of the adult male and female, sub-adult and yearling lines to the right is because increases of 5\% - 10\% in survival rate results in 100\% survival in these classes. FIGURE 6: Sensitivity of the population growth rate to changes in survival rate of different age classes of sable on the Malilangwe Wildlife Reserve. 
by comparing the modelled trend to the observed trend in the population over the past 5 years. The observed population fluctuated above and below the modelled population, which showed a steady increase from 2005 to 2010, a result of taking an average of 500 iterations. The short duration of the study meant that the effect of environmental stochasticity was essentially excluded from the model. However, testing of the output against historical data lent strong support to the model parameters despite the limited period of observation.

Replicating the declining trend of the sable population from 2000 to 2005 proved more challenging as it was clear that, under current conditions, the sable population on the MWR was predicted to increase. Historical data on the number of sable carcasses found by scouts on patrol clearly indicated a period of considerably higher mortality in sable from 2000 to 2005 (Table 3), particularly amongst the older age classes. This period coincides with a period of markedly higher lion numbers at the MWR (Figure 7). Of the total number of sable carcasses found from 2000 to 2005, 70\% were attributed to lion predation. Lions show a clear preference for mediumbodied to large-bodied prey (Hayward \& Kerley 2005) and this was evident in the fact that $88 \%$ of sable killed by lions between 2000 and 2010 fell into the adult and sub-adult age classes. This fact further justified the factoring of the vital rates for the 2000-2005 period. The output from the model followed the observed trend well, again lending support for the estimates of the vital rates for the period 2000-2005. The rate of decline over this period was -0.1209 (s.d. $=0.0777$ ), markedly higher than that reported by Nicholls et al. (1996) for the KNP between 1983 and 1992.

Under the current conditions, the sable population on the MWR is predicted to remain viable, steadily increasing to carrying capacity over the next 30 years. However, the sensitivity analysis shows that even a small change in adult female survival $(10 \%)$ could have disastrous effects. Even more alarming is that a $10 \%$ reduction in survival of adult females equates to a total loss of only four adult female sable per year. This means that the sable population on the MWR, although currently stable, remains highly vulnerable to changes in predation pressure, environmental and demographic stochasticity and management interventions. Similarly, sable antelope in the KNP are at serious risk of extinction within the next 100 years (Nicholls et al. 1996) and Owen-Smith et al. (2005) attribute the decline of the species there to increased predation by lions. On the MWR, evidence points to a similar pattern where increased lion numbers were primarily driving the decline of the species until 2005 (Figure 7). In 2005, emigration of two lion prides effectively halved the lion population (Figure 7), following an outbreak of anthrax that devastated prey populations in 2004 (Clegg et al. 2007). Since then, the relatively high rate of juvenile mortality has prevented the sable population from growing at its full potential.

The long-term growth rate of a population can be used as a direct measure of the fitness of that population (Ranta, Lundberg \& Kaitala 2006) and, as such, changes in the demographic components within the population can have direct impacts on its overall viability. Sensitivity analyses can determine which vital rates have the greatest impact on overall population growth and thus fitness. Examining the results from the sensitivity analysis allows one not only to determine which demographic parameters have the greatest impact on overall population growth, but to assess the effect of variability or uncertainty in these parameters. The finding that a change in adult female survival has the greatest effect on overall population growth rate is not unusual and has been documented for other taxa (Gaillard et al. 2000; Saether $\&$ Bakke 2000). The extent of this sensitivity in relation to that

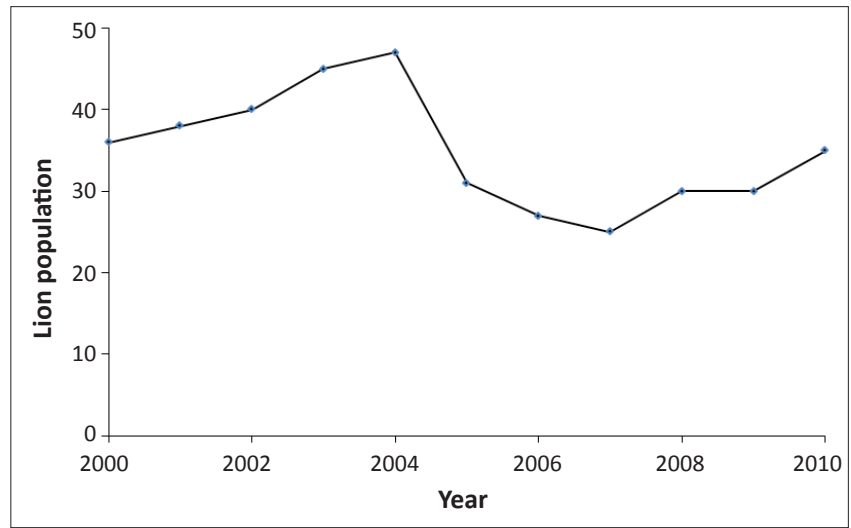

Source: Clegg, B.W., 2011, 'Lion population estimates for Malilangwe Wildlife Reserve between 2000 and 2010', Unpublished internal report for the Malilangwe Trust, Zimbabwe FIGURE 7: Estimates of lion population on the Malilangwe Wildlife Reserve from 2000 to 2010, taken from call ups, spoor counts and known pride numbers.

TABLE 3: Causes of death of sable carcasses discovered by the Malilangwe Wildlife Reserve scout force on their daily patrols between 2000 and 2010.

\begin{tabular}{|c|c|c|c|c|c|c|c|c|c|c|}
\hline Year & Disease & Electric fence & Leopard & Lion & Poaching & Hyena & Wild dog & $\begin{array}{l}\text { Unknown } \\
\text { predator }\end{array}$ & $\begin{array}{l}\text { Unknown } \\
\text { cause }\end{array}$ & Total \\
\hline 2000 & - & 2 & 1 & 4 & - & 1 & - & - & - & 8 \\
\hline 2001 & - & 1 & - & 3 & - & - & - & - & 1 & 5 \\
\hline 2002 & - & - & - & 1 & - & - & - & 1 & - & 2 \\
\hline 2003 & 1 & - & - & 6 & - & - & - & - & - & 7 \\
\hline 2004 & 2 & - & - & 2 & - & - & - & - & - & 4 \\
\hline 2005 & - & - & - & 7 & - & - & - & - & - & 7 \\
\hline 2006 & - & - & - & - & - & - & - & - & - & 0 \\
\hline 2007 & - & - & - & - & - & - & - & - & - & 0 \\
\hline 2008 & - & - & - & 1 & 1 & - & - & - & 1 & 3 \\
\hline 2009 & - & - & - & 1 & - & - & - & - & - & 1 \\
\hline 2010 & - & - & - & - & - & - & 1 & - & - & 1 \\
\hline Total & 3 & 3 & 1 & 25 & 1 & 1 & 1 & 1 & 2 & 38 \\
\hline
\end{tabular}


of other age classes indicates that the historic decline of the species on the MWR must have been caused by, inter alia, an increase in mortality in the adult female age class. This observation again lends support to the theory that increased predation, particularly by lions, was responsible for the decline of the species. In general, Gaillard et al. (1998) state that adult survival amongst large ungulates is always less variable than juvenile mortality and attribute this to the fact that recruitment is often the foremost target of limiting factors, both density-dependent and independent. Highly variable juvenile mortality has been linked to population declines (Gaillard et al. 1998) and Owen-Smith and Mason (2005) state that variations in juvenile survival could be a key factor responsible for fluctuations in population numbers. On the MWR, it seems unlikely that juvenile mortality alone could be responsible for the decline of the species from 2000 to 2005 , based on the fact that a reduction in juvenile survival of as much as $25 \%$ still led to an overall positive growth rate in the population. It is possible to suggest, however, that variable juvenile mortality potentially causes short-term fluctuations in the population growth rate and increased mortality targeting the adult segment of the population is the driving factor in long-term sharp declines.

\section{Management implications}

Using baseline data designed to simulate conditions observed from 2000 to 2005, the PVA model predicted a local extinction of the sable population on the MWR within the next 20 years. The augmentation of the population under these circumstances does little to curb the trend and management would need to look at ways of reducing the rate of mortality in the older age classes. This is similarly the case with roan antelope (Hippotragus equinus) in the KNP, where predation risk remains high for adult roan and augmentation of the free-range population is seen as being a wasteful option at this stage (McLoughlin \& Owen-Smith 2003). In the longterm, manipulation of water points on the MWR to reduce the density of other herbivores and thus predators within the range of the sable herds may be a feasible option. However, managers within the KNP have attempted this with limited success (McLoughlin \& Owen-Smith 2003). McLoughlin and Owen-Smith (2003) suggest this could be because of only a partial emigration by predators from these areas. These authors warn that reducing the density of other herbivores in these areas may leave predators more reliant on the low density ungulates, with devastating consequences. A further complication arises because water points are an important resource for many other species, as well as being a focus of ecotourists on the MWR. Therefore, with the limited number of alternatives, some control of predators, particularly lions, in combination with a review of artificial water management practices may be necessary to reduce the predation risk faced by the sable population. The management implications of controlling predator numbers have been poorly studied, however, so investigations into the methods and effects of predator control are required.

\section{Conclusion}

The sable population on the MWR is vulnerable to declines. Adult female mortality showed the greatest sensitivity and indicated that the decline of sable on the MWR was driven by, inter alia, an increase in mortality in the adult female segment of the population. The results suggest that predation was the main driver of the historic decline on the MWR and future declines could be prevented through reducing the risk of predation on the sable population. These findings underpin the importance of effective management of predator populations in small-enclosed reserves, ideally achieved through better management of artificial water distribution. We recommend that future research should focus on the management of artificial water and its implications for predator numbers and the development of predator refuges.

\section{Acknowledgements}

This study was carried out as a collaboration between the Department of Conservation Ecology and Entomology at the University of Stellenbosch and the Malilangwe Wildlife Research Department. The study was conducted under the ethical guidance of the Malilangwe Trust and its Board of Trustees and licensed professionals were used where necessary in all cases. We would like to thank the Malilangwe Trust for providing us with the resources and funding needed to make this study possible. Several people are thanked for assisting with fieldwork, in particular: C. Wenham, B. Fivaz, P. Chivambu, K. Mahuhle, P. Chitimela and G. Coombes.

\section{Competing interests}

The authors declare they have no financial or personal relationships which may have inappropriately influenced them in writing this article.

\section{Authors' contributions}

S.D.C. (Stellenbosch University) was the primary field researcher and MSc student on whose dissertation this article is based. A.J.L. (Stellenbosch University) was the project leader and student's supervisor, whilst B.C. (Malilangwe Wildlife Reserve) was the on-site ecologist an d co-supervisor. All three authors were responsible for the experimental and research design and production of the final manuscript.

\section{References}

Begon, M., Harper, J.L. \& Townsend, C.R., 1996, Ecology: Individuals, populations and communities, Blackwell, Oxford. http://dx.doi.org/10.1002/9781444313765

Booth, V.R., 1980, 'A study on Lichtenstein's hartebeest, Alcelaphus lichtensteini (Peters 1852) and its habitat in south-eastern Rhodesia', MSc thesis, University of Pretoria.

Boyce, M.S., 1992, 'Population viability analysis', Annual Review of Ecology and Systematics 23, 481-506. http://dx.doi.org/10.1146/annurev.es.23.110192. 002405

Brook, B.W., O'Grady, J.J., Chapman, A.P., Burgman, M.A., Akçakaya, H.R. \& Frankham, R., 2000, 'Predictive accuracy of population viability analysis in conservation biology', Nature 404, 385-387. http://dx.doi.org/10.1038/35006050, PMid:10746724

Cancino, J., Rodriguez-Estrella, R. \& Miller, P. 2010, 'Using a population viability analysis for management recommendations of the endangered endemic peninsular pronghorn', Acta Zoologica Mexicana (n.s.) 26, 173-189. 
Caughley, G., 1966, 'Mortality patterns in mammals', Ecology 47, 906-917. http:// dx.doi.org/10.2307/1935638

Clegg, B.W., 2010, 'Habitat and diet selection by the African elephant at the landscape level: A functional integration of multi-scale foraging processes', PhD thesis, University of the Witwatersrand.

Clegg, B.W., 2011, 'Lion population estimates for Malilangwe Wildlife Reserve between 2000 and 2010', Unpublished internal report for the Malilangwe Trust, Zimbabwe.

Clegg, S.B., Turnbull, P.C.B., Foggin, C.M. \& Lindeque, P.M., 2007, 'Massive outbreak of anthrax in wildlife in the Malilangwe Wildlife Reserve, Zimbabwe', Veterinary Record 160, 113-118. http://dx.doi.org/10.1136/vr.160.4.113, PMid:17259452

Coulson, T., Mace, G.M., Hudson, E. \& Possingham, H.P., 2001, 'The use and abuse of population viability analysis', Trends in Ecology and Evolution 16, 219-221. http:// dx.doi.org/10.1016/S0169-5347(01)02137-1

Ellner, S.P., Fieberg, J., Ludwig, D. \& Wilcox, C., 2002, 'Precision of population viability analysis', Conservation Biology 16, 258-261. http://dx.doi.org/10.1046/j.15231739.2002.00553.x

Gaillard, J.M., Festa-Bianchet, M. \& Yoccoz, N.G., 1998, 'Population dynamics of large herbivores: Variable recruitment with constant adult survival', Trends in Ecology and Evolution 13, 58-63. http://dx.doi.org/10.1016/S0169-5347(97)01237-8

Gaillard, J.M., Festa-Bianchet, M., Yoccoz, N.G., Loison, A. \& Toigo, C., 2000, 'Temporal variation in fitness components and population dynamics of large herbivores', Annual Review of Ecology and Systematics 31, 367-393. http://dx.doi. org/10.1146/annurev.ecolsys.31.1.367

Ginsberg, J.R., Mace, G.M. \& Albon, S., 1995, 'Local extinction in a small and declining population: Wild dogs in the Serengeti', Proceedings: Biological Sciences 262, 221-228. http://dx.doi.org/10.1098/rspb.1995.0199, PMid:8524914

Goodman, P.S., 2009, 'Large mammal population estimates for Malilangwe estate', Unpublished report for the Malilangwe Trust, Zimbabwe.

Grant, C.C. \& Van der Walt, J.L., 2000, 'Towards an adaptive management approach for the conservation of rare antelope in the Kruger National Park: Outcome of a workshop held in May 2000', Koedoe 43, 103-112. http://dx.doi.org/10.4102/ koedoe.v43i2.202

Grobler, J.H., 1980a, 'Body growth and age determination of the sable Hippotragus niger niger (Harris, 1838)', Koedoe 23, 131-156. http://dx.doi.org/10.4102/ koedoe.v23i1.641

Grobler, J.H., 1980b, 'Breeding biology and aspects of social behaviour of sable Hippotragus niger niger (Harris, 1838) in the Rhodes Matopos National Park, Zimbabwe', South African Journal of Wildlife Research 10, 149-153.

Gusset, M., Jakoby, O., Muller, M.S., Somers, M.J., Slotow, R. \& Grimm, V., 2009, 'Dogs on the catwalk: Modelling re-introduction and translocation of endangered wild dogs in South Africa', Biological Conservation 142, 2774-2781. http://dx.doi. org/10.1016/j.biocon.2009.07.007
Harrington, R., Owen-Smith, N., Viljoen, P.C., Biggs, H.C., Mason, D.R. \& Funston, P., 1999, 'Establishing the causes of the roan antelope decline in Kruger National Park, South Africa', Biological Conservation 90, 69-78. http://dx.doi.org/10.1016/ S0006-3207(98)00120-7

Hayward, M.W. \& Kerley, G.I.H., 2005, 'Prey preferences of the lion (Panthera leo)', Journal of Zoology, London 267, 309-322. http://dx.doi.org/10.1017/ S0952836905007508

Kelly, M.J. \& Durant, S.M., 2000, 'Viability of the Serengeti cheetah population', Conservation Biology 14, 786-797. http://dx.doi.org/10.1046/j.1523-1739. 2000.98329.x

Lacy, R.C., Borbat, M. \& Pollak, J.P., VORTEX: A stochastic simulation of the extinction process, Computer software, version $9.99 \mathrm{~b}$, viewed March 2009, from http:// www.vortex9.org/vortex.html

McLoughlin, C.A. \& Owen-Smith, N., 2003, 'Viability of a diminishing roan antelope population: Predation is the threat', Animal Conservation 6, 231-236. http:// dx.doi.org/10.1017/S1367943003003287

Nicholls, A.O., Viljoen, A.J., Knight, M.H. \& Van Jaarsveld, A.S., 1996, 'Evaluating population persistence of censused and unmanaged herbivore populations from the Kruger National Park, South Africa', Biological Conservation 76, 57-67. http:// dx.doi.org/10.1016/0006-3207(95)00094-1

Nijhof, A.M., Pillay, V., Steyl, J., Prozesky, L., Stoltsz, W.H., Lawrence, J.A. et al., 2005, 'Molecular characterisation of Theilleria species associated with mortality in four species of African antelope', Journal of Clinical Microbiology 43, 59075911. http://dx.doi.org/10.1128/JCM.43.12.5907-5911.2005, PMid:16333074 PMCid:1317158

Oosthuizen, M.C., Zweygarth, E., Collins, N.E., Troskie, M. \& Penzhorn, B.L., 2008 'Identification of a novel Babesia sp. from a sable antelope (Hippotragus niger Harris, 1838)', Journal of Clinical Microbiology 46, 2247-2251. http://dx.doi. org/10.1128/JCM.00167-08, PMid:18508943 PMCid:2446884

Owen-Smith, N. \& Mason, D.R., 2005, 'Comparative changes in adult vs juvenile survival affecting population trends of African ungulates', Journal of Animal Ecology 74, 762-773. http://dx.doi.org/10.1111/j.1365-2656.2005.00973.x

Owen-Smith, N. \& Mills, G., 2008, 'Predator-prey size relationships in an African large-mammal food web', Journal of Animal Ecology 77, 173-183. http://dx.doi. large-mammal food web', Journal of Animal Ecology 77,
org/10.1111/j.1365-2656.2007.01314.x, PMid:18177336

Owen-Smith, N., Mason, D.R. \& Ogutu, J.O., 2005, 'Correlates of survival rates for 10 African ungulate populations: Density, rainfall and predation', Journal of Animal Ecology 74, 774-788. http://dx.doi.org/10.1111/j.1365-2656.2005.00974.x

Ranta, E., Lundberg, P. \& Kaitala, V., 2006, Ecology of populations, Cambridge University Press, New York. PMCid:1634913

Saether, B.E. \& Bakke, E.O., 2000, 'Avian life history variation and contribution of demographic traits to the population growth rate', Ecology 81, 642-653.

Taylor, B.L., 1995, 'The reliability of using population viability analysis for risk classification of species', Conservation Biology 9, 551-558. http://dx.doi. org/10.1046/j.1523-1739.1995.09030551.x 